\title{
Facile preparation of sago starch esters using full factorial design of experiment
}

\author{
Felycia Edi Soetaredjo ${ }^{1}$, Suryadi Ismadji ${ }^{2}$, Lien Huong Huynh ${ }^{1}$, Novy S. Kasim ${ }^{1}$, \\ Ngoc Yen Tran-Thi ${ }^{1}$, Aning Ayucitra ${ }^{2}$ and Yi-Hsu Ju ${ }^{1}$ \\ ${ }^{1}$ Department of Chemical Engineering, National Taiwan University of Science and Technology, Taipei, Taiwan \\ ${ }^{2}$ Department of Chemical Engineering, Widya Mandala Surabaya Catholic University, Kalijudan, Surabaya, Indonesia
}

\begin{abstract}
A facile solvent-free method to acetylate sago starch (Metroxylon sagu) is reported. Microwave $(100 \mathrm{~W})$ was used as the heating source and the heating time was varied from 2 to $10 \mathrm{~min}$ with the temperature of acetylation maintained at $100^{\circ} \mathrm{C}$ under continuous stirring. Using a $2^{4}$ full factorial design of experiment, it was found that the degree of substitution (DS) of acetylated sago starch was strongly affected by the ratio of starch to acylating reagents, the ratio of acetic anhydride to acetic acid as the acylating reagents, the concentration of iodine as catalyst and reaction time. The physicochemical characteristics of the acetylated sago starch were assessed based on the FTIR spectra, the XRD spectra, the water absorption index (WAI), and the water solubility index (WSI). SEM was used to study the surface morphology of the acetylated sago starch at different DS.
\end{abstract}

\section{Keywords:}

Acetylation / Microwave / Sago Starch

\section{Introduction}

Palms (such as sago palm (Metroxylon sagu)) constitute one of the oldest plant families on Earth. Sago palm grows well in tropical peat swamp rainforests, where other crop plants do not. It has great potential for starch production. Sago starch is extracted from sago pith and a single sago palm yields about 150-300 kg starch [1].

Grain of sago starch prepared from palm pith is small, whitish, pinkish, or brownish. Sago starch is exported to Europe and America for thickening soup and making puddings. In Indonesia and India, it is boiled with sugar to make jelly and porridge. Sago starch support the production of other types of food such as noodles, mono-

Correspondence: Professor Yi-Hsu Ju, Department of Chemical Engineering, National Taiwan University of Science and Technology, 43 sec 4 . Keelung Rd., Taipei, Taiwan

E-mail: yhju@ mail.ntust.edu.tw

Fax: $+886-2-2737-6644$

Abbreviations: DOE, design of experiment; DS, degree of substitution; WAI, water absorption index; WSI, water solubility index
Received: October 31, 2011

Revised: January 29, 2012

Accepted: February 2, 2012 sodium glutamate, and soft drinks. In addition to being used as foodstuff, sago starch is also utilized to produce adhesive for paper, textiles, and plywood; as a stabilizer in pharmaceuticals; as raw material for producing biodegradable plastics, fuel alcohol, and ethanol [2].

In order to enhance and extend applications the mechanical properties of natural sago starch can be modified by altering its structure (e.g., affecting the hydrogen bonding of $\mathrm{AM}$ and $\mathrm{AP}$ in a controllable manner). Most common starch modifications in industry involve cross-linking, esterification, and etherification. Acetylated starch is the most typical starch ester in the market. Acetylation can be performed with relative ease to significantly improve the physicochemical and functional properties of the starch, such as lower gelatinization and pasting temperatures; improved freeze-thaw stability of pastes and gels; improved paste stability; higher redispersibility when pregelatinized; and greater clarity of paste and gel [3-5].

Acetylated starch (degree of substitution, $D S<0.09$ ) is used in many bakery, frozen and canned foods products and is also present in white salted noodles to improve

Colour online: See the article online to view Fig. 1 in colour. 
texture, stability, and appearance [6]. Acetylated starch with DS higher than 0.09 has been used for non-food applications such as tablet binders, hot melt adhesives, coatings, cigarette filters, biodegradable plastics, and metal ion absorbents [7-11].

Acetylation is accomplished by treating starch slurry with acetic anhydrade and sodium hydroxide [3, 5, 12], acetic anhydride and pyridine [13], and acetic anhydride and vinyl acetate [14]. However, this process uses a lot of chemically treated water to maintain $\mathrm{pH}$ and can cause wastewater handling problems and is time consuming. In this process certain reagents may be needed to rupture or weaken intermolecular bonds of starch to obtain high DS [15]. A simple solvent-free 10 min method was proposed to acetylate starch and other polysaccharides such as cellulose, corn starch, and potato starch [4, 7, 12, 15, 16]. No similar produce for sago starch has been published.

Many factors are considered in selecting a reagent and preparative method. The reactivity of the reagent used is important to obtain high DS. Acetic anhydride in the presence of iodine as the catalyst is an excellent acylating reagent for both starch and cellulose [7, 15-17]. However the use of acetic anhydride is permitted within specified limitation for foodstuffs by The United State Food and Drug Administration [18]. Acetic acid is a safe reagent for starch acetate intended for foods products. lodine as a catalyst activates the carbonyl group of acetic anhydride, which works only in the absence of a solvent. For both solvent-free and aqueous based reaction systems, microwave radiation is used as the energy source to reduce the reaction time. The objective of this study is to investigate the influence of acylating reagent (acetic anhydride and acetic acid, iodine), the ratio of starch-acylating reagent and heating time on the DS of acetylated sago starch using the solvent-free method as well as to evaluate the properties of the resulting products.

\section{Materials and methods}

\subsection{Materials}

Commercial sago starch from Riau Indonesia was sieved passing 60 mesh and dried at $50^{\circ} \mathrm{C}$ for $24 \mathrm{~h}$ before processing (moisture content about 3.36\%). Acetic acid $(\geq 99 \%)$ and acetic anhydride $(\geq 98 \%)$ were analytical grade from Sigma-Aldrich (St. Louis, USA). Sodium thiosulfate, ethanol, iodine, and potassium hydroxide were supplied by Merck (Darmstadt, Germany). Hydrochloric acid was obtained from Fluka (Steinheim, Germany). All chemical used in this work were analytical grade.

\subsection{Synthesis of starch acetate}

A $4 \mathrm{~g}$ sago starch sample $(24.5 \mathrm{mmol}$ of anhydroglucose unit or AGU [15]) was put into a $50 \mathrm{~mL}$ round-bottom glass flask with a magnetic stirrer, followed by a mixture of acylating reagents (acetic acid and acetic anhydride) and iodine (as the catalyst). Then, the round-bottom glass flask was placed in a microwave reactor (Microwave CEM Atmospheric Pressure, Microwave Synthesis/Extraction System, Matthews NC, USA), equipped with a reflux condenser. The acetylation was performed at $100^{\circ} \mathrm{C}$ under continuous stirring and $100 \mathrm{~W}$ of microwave radiation. After a certain reaction time, the flask was cooled to $<50^{\circ} \mathrm{C}$, then was removed from the microwave oven and cooled to room temperature. Variables such as ratio of starch to acylating reagent, ratio of acetic acid to acetic anhydride, amount of iodine and reaction time, that affect the reaction were studied using a $2^{4}$ full factorial design of experiment (DOE; Table 1).

A saturated solution of sodium thiosulfate was added to the mixture and stirred until the mixture color changed from dark brown to colorless, indicating the transformation of iodine to iodide [16]. Then, ethanol was added to precipitate the mixture. The mixture was filtered, washed with ethanol and distilled water to remove the unreacted acetic acid and byproducts. The acetylated sago starch was dried in a vacuum oven (Lab-Line Duo-Vac Oven, Lab-Line Instrument Inc., Melrose Park, ILL, USA) at $60^{\circ} \mathrm{C}$ for $3 \mathrm{~h}$. The dried acetylated starches obtained under different conditions were ground to fine powder before being analyzed further.

\subsection{Determination of the degree of substitution (DS)}

Degree of substitution was determined by the complete basic hydrolysis of the ester linkages and titration of the excess alkali, following the method used by [16].

Table 1. Variables considered for DOE and their levels

\begin{tabular}{llll}
\hline Parameters & Low level $(-1)$ & Center point $(0)$ & High level $(+1)$ \\
\hline Mole ratio of starch to acylation reagents (A) & $1: 2$ & $1: 3$ & $1: 4$ \\
Mole ratio of acetic anhydride to acetic acid (B) & $1: 0$ & $1: 1$ & $0: 1$ \\
lodine catalyst (\%mole of starch) (C) & 0.15 & 2.58 & 5 \\
Reaction time (min) (D) & 2 & 6 & 10 \\
\hline
\end{tabular}


Acetyl content $(\% A)$ was calculated based on the following equations:

$\% A=\frac{\left(V_{0}-V_{n}\right) \times N \times 43 \times 10^{-3} \times 100}{M}$

where $V_{0}$ and $V_{n}$ are volume $(\mathrm{mL})$ of $\mathrm{HCl}$ used to titrate blank and sample, respectively; $N$ is the normality of used $\mathrm{HCl}, M$ is sample amount as dry substance $(\mathrm{g}), 43$ is the MW of acetyl group.

Acetyl content $(\% A)$ was used to calculate the DS:

$\mathrm{DS}=162 \times \frac{\% A}{[43 \times 100-(43-1 \times \% A)]}$

where 162 is the MW of the anhydroglucose unit, 1 is the hydrogen mass.

\subsection{Fourier transform-infra red (FT-IR) analysis}

FT-IR spectra of native and acetylated sago starch were acquired on a Shimadzu 8400 S FT-IR (Shimadzu Corporation, Kyoto, Japan) using potassium bromide $(\mathrm{KBr})$ method.

\subsection{XRD analysis}

Powder XRD patterns of native and acetylated sago starch ( $D S=1.2$ ) were recorded on a Rigaku Miniflex Goniometer at $30 \mathrm{kV}$ and $15 \mathrm{~mA}$, using $\mathrm{Cu} \mathrm{K} \alpha$ radiation at a step size of $0.01^{\circ}$.

\subsection{SEM analysis}

The morphological features of native and acetylated sago starch with different DS were observed with a Cambridge scanning electron microscope (S-360) at an accelerating voltage of $20 \mathrm{kV}$. Dried starch granules were mounted on a double-sided tape attached to a metal stub and sputtered with gold in order to make the sample conductive.

\subsection{Water absorbance index (WAI) and water solubility index (WSI)}

Water absorption index (WAI) and water solubility index (WSI) of native and acetylated sago starch were measured using a modified method of AACC method 56-20. The experimental detail was described by [16]. WAI $(\mathrm{g} / \mathrm{g})$ and WSI (\%) were calculated by the following equations:

$\mathrm{WAI}=\left[W_{\mathrm{s}}-W_{\mathrm{t}} / W_{1}\right]$

where $W_{\mathrm{s}}$ is weight of the tube with the sediment, $W_{\mathrm{t}}$ is weight of the empty tube, and $W_{1}$ is weight of the dry sample and

$\mathrm{WSI}=\left[W_{3}-W_{2} / W_{1}\right] \times 100$ where $W_{3}$ is weight of the dish and with dry solute, $W_{2}$ is weight of the empty dish and $W_{1}$ is weight of the dry sample.

\subsection{Statistical analysis}

The statistical DOE involved the simultaneous study of several process variables in the acetylation of sago starch. The significance of each factor and their interaction effects were evaluated by using two-level full factorial DOEs [19]. The potential variables were classified as controlled variables (Table 1) and constant variables. Constant variables such as reaction temperature, agitation speed, and microwave power were held at $100^{\circ} \mathrm{C}$, medium stirring (equipment setting), and $100 \mathrm{~W}$, respectively. Each controlled variables were kept at three levels, high level $(+1)$, center point (0), and lower level $(-1)$ as listed in Table 1. After conducting all trials, results were analyzed by analysis of variance (ANOVA) technique using Minitab 14 software.

\section{Results and discussion}

\subsection{Effect of variables on DS}

Facile preparation of starch acetate was performed by the reaction of starch with acylating reagents (acetate anhydride and acetic acid) using iodine as the catalyst and with the assistance of microwaves. The matrix for four variables varied at two levels $(+,-)$ and the corresponding DS obtained are shown in Table 2 according to DOE. In the range of variables studied, the highest DS obtained is 1.202 .

The determination of the significant factors affecting DS was done by performing two-way ANOVA (Table 3). After the effects of individual factors were assessed using factorial design; it turned out that the ratio of starch to acylating agent, the ratio of acetic anhydride to acetic acid and the iodine concentration all are significant factors $(p<0.05)$ while the reaction time was not $(p>0.05)$. For the assessment of two variables interaction, all binary interactions were showed to have significant effect on DS $(p<0.05)$. The ANOVA result also showed that three level interactions were insignificant when reaction time was excluded from the assessment. This demonstrated that individual factor interaction in the synthesis of starch acetate was not significant but the interaction between variables determines the DS of starch acetate.

The effect of four variables used in this study is also shown in Table 3 . The ratio of acylating agent (acetic anhydride and acetic acid) and reaction time have a negative effect on the DS. Using microwave energy as heating source caused permanent electric dipoles and monopoles 
Table 2. DS results from the experimental runs of $2^{4}$ full factorial design

\begin{tabular}{llllll}
\hline Standard & & & & & \\
run & A & B & C & D & DS \\
\hline 20 & + & + & - & - & 0.166 \\
12 & + & + & - & + & 0.016 \\
22 & + & - & + & - & 1.202 \\
1 & - & - & - & - & 0.180 \\
19 & - & + & - & - & 0.175 \\
16 & + & + & + & + & 0.531 \\
26 & + & - & - & + & 0.170 \\
9 & - & - & - & + & 0.101 \\
5 & - & - & + & - & 0.754 \\
18 & + & - & - & - & 0.295 \\
27 & - & + & - & + & 0.111 \\
24 & + & + & + & - & 0.169 \\
15 & - & + & + & + & 0.097 \\
28 & + & + & - & + & 0.016 \\
21 & - & - & + & - & 0.846 \\
17 & - & - & - & - & 0.174 \\
4 & + & + & - & - & 0.174 \\
30 & + & - & + & + & 1.267 \\
6 & + & - & + & - & 1.138 \\
3 & - & + & - & - & 0.167 \\
8 & + & + & + & - & 0.185 \\
2 & + & - & - & - & 0.275 \\
11 & - & + & - & + & 0.123 \\
31 & - & + & + & + & 0.109 \\
33 & 0 & 0 & 0 & 0 & 0.131 \\
29 & - & - & + & + & 0.692 \\
10 & + & - & - & + & 0.158 \\
23 & - & + & + & - & 0.159 \\
13 & - & - & + & + & 0.804 \\
32 & + & + & + & + & 0.591 \\
7 & - & + & + & - & 0.163 \\
14 & + & - & + & + & 1.095 \\
25 & - & - & - & + & 0.089 \\
\hline & & & & & \\
\hline & + & + & + & +
\end{tabular}

(ionic charges), in which a portion of the incident energy was reflected from it and the remaining energy was transmitted into the material. By random collisions with neighboring molecules, the dipoles transferred energy, resulting in a temperature rise in the material. When acetic acid and acetic anhydride are heated by microwaves, their temperatures rise to about 1.5 times and 2 times, respectively, of that of water for the same energy input $[16,20]$. Therefore, acetic anhydride is a better acylating agent to obtain higher DS of starch acetate than acetic acid. For longer reaction time, this phenomenon may cause breakdown of starch acetate and result in lower DS [7, 15].

The ratio of starch to acylating reagents and iodine concentration had a positive effect on DS. The ratio of starch to acylating reagents was found to be important, but the amount of iodine was the most important factor $[5,7$,
16]. Iodine has a great ability to absorb microwaves to improve the reaction and shortens the reaction time [21]. lodine is able to accept two pairs of electrons from other reactants since it acts as a Lewis acid catalyst. lodine is able to activate the carbonyl carbon of acetic anhydride and makes it more reactive $[7,16]$.

The regression model with interaction terms can be written using Taylor series of expansion as:

$$
\begin{aligned}
Y= & b_{0}+b_{1} x_{1}+b_{2} x_{2}+b_{3} x_{3}+b_{4} x_{4}+b_{12} x_{1} x_{2}+b_{13} x_{1} x_{3} \\
& +b_{14} x_{1} x_{4}+b_{23} x_{2} x_{3}+b_{24} x_{2} x_{4}+b_{34} x_{3} x_{4} \\
& +b_{123} x_{1} x_{2} x_{3}+b_{124} x_{1} x_{2} x_{4}+b_{134} x_{1} x_{3} x_{4}+b_{234} x_{2} x_{3} x_{4} \\
& +b_{1234} x_{1} x_{2} x_{3} x_{4}
\end{aligned}
$$

where $Y$ is $\mathrm{DS} ; b_{i}$ is model coefficients and $x_{1}, x_{2}, x_{3}$, and $x_{4}$ are dimensionless coded factors for mole ratio of starch to acylation reagents, mole ratio of acetic anhydride to acetic acid, iodine catalyst concentration and reaction time, respectively. Neglecting the coefficients of nonsignificant terms at $95 \%$ confidence level, the regression becomes:

$Y=0.3810+0.0845 x_{1}-0.1965 x_{2}+0.2316 x_{3}-0.0079 x_{4}$

In the range of variables considered in this paper, the regression is applicable to synthesize acetylated sago starch at low DS up to DS $=1$.

\subsection{Physicochemical properties}

\subsubsection{Fourier transform-infra red (FT-IR) analysis}

FTIR spectra provide a rapid and reliable method for evaluating the extent of acetylation in starches. The FTIR spectra of native sago starch and starch acetate are shown in Fig. 1. In the IR spectra, native sago starch attributed to the $\mathrm{C}-\mathrm{O}$ bond stretching at 1078, 1154 , and $1267 \mathrm{~cm}^{-1}$. Other absorption at around $1650 \mathrm{~cm}^{-1}$ corresponds to the bound water $\left(\mathrm{H}_{2} \mathrm{O}\right)$ in the starch; absorption at $3500 \mathrm{~cm}^{-1}$ is resulting from the vibration of the hydroxyl group $(\mathrm{O}-\mathrm{H})$ and the absorption near $3000 \mathrm{~cm}^{-1}$ can be attributed to the $\mathrm{C}-\mathrm{H}$ vibration stretch $[7,12,16]$.

New absorption peaks appeared after acetylation using acetic anhydride and acetic acid especially for high DS (0.8 and 1.2). By comparing the spectra of native sago starch and high DS of starch ester, the new peaks at 1750, 1435, and $1370 \mathrm{~cm}^{-1}$ are assigned to the carbonyl $\mathrm{C}=\mathrm{O}$, the $\mathrm{CH}_{3}$ anti-symmetry deformation vibration and the $\mathrm{CH}_{3}$ symmetry deformation vibration, respectively. These new absorption bands suggest that the ester carbonyl groups were formed during acetylation. The peak intensity of $1750-1735 \mathrm{~cm}^{-1}$ for $\mathrm{C}=\mathrm{O}$ stretching vibrations of saturated aliphatic esters is greatly affected by the DS since the 
Table 3. DS ANOVA table for sago starch acetylation

\begin{tabular}{|c|c|c|c|c|c|}
\hline Factors/Interactions & Effect & Coef & SE Coef & $\mathrm{T}$ & $\mathrm{P}$ \\
\hline Constant & & 0.3810 & 0.007635 & 49.90 & 0.000 \\
\hline A & 0.1690 & 0.0845 & 0.007635 & 11.07 & 0.000 \\
\hline$B$ & -0.3930 & -0.1965 & 0.007635 & -25.74 & 0.000 \\
\hline C & 0.4632 & 0.2316 & 0.007635 & 30.34 & 0.000 \\
\hline $\mathrm{D}$ & -0.0158 & -0.0079 & 0.007635 & -1.03 & 0.318 \\
\hline$A \times B$ & -0.0760 & -0.0380 & 0.007635 & -4.98 & 0.000 \\
\hline$A \times C$ & 0.1502 & 0.0751 & 0.007635 & 9.84 & 0.000 \\
\hline$A \times D$ & 0.0458 & 0.0229 & 0.007635 & 3.00 & 0.009 \\
\hline$B \times C$ & -0.3313 & -0.1656 & 0.007635 & -21.69 & 0.000 \\
\hline$B \times D$ & 0.0452 & 0.0226 & 0.007635 & 2.96 & 0.009 \\
\hline$C \times D$ & 0.0870 & 0.0435 & 0.007635 & 5.70 & 0.000 \\
\hline$A \times B \times C$ & -0.0063 & -0.0031 & 0.007635 & -0.41 & 0.688 \\
\hline$A \times B \times D$ & 0.0398 & 0.0199 & 0.007635 & 2.60 & 0.019 \\
\hline$A \times C \times D$ & 0.0805 & 0.0403 & 0.007635 & 5.27 & 0.000 \\
\hline$B \times C \times D$ & 0.0465 & 0.0232 & 0.007635 & 3.04 & 0.008 \\
\hline$A \times B \times C \times D$ & 0.0550 & 0.0275 & 0.007635 & 3.60 & 0.002 \\
\hline Centre point & & -0.2500 & 0.043863 & -5.70 & 0.000 \\
\hline \multicolumn{6}{|l|}{$S=0.0431929$} \\
\hline \multicolumn{6}{|l|}{$\mathrm{R}-\mathrm{Sq}=99.35 \%$} \\
\hline $\mathrm{R}-\mathrm{Sq}(\mathrm{adj})=98.70 \%$ & & & & & \\
\hline
\end{tabular}

relative intensity become stronger with increasing DS (Table 4) $[5,16,22]$. The new peaks for the $\mathrm{CH}_{3}$ antisymmetry deformation vibration $\left(1435 \mathrm{~cm}^{-1}\right)$ and the $\mathrm{CH}_{3}$ symmetry deformation vibration $\left(1370 \mathrm{~cm}^{-1}\right)$ show clearly at high DS indicating acetylation cause the starch molecule deformation. For native starch, there are two peaks at 1428 and $1454 \mathrm{~cm}^{-1}$ and then after acetylation become one peak with weak relative intensity (Table 4). With increasing $\mathrm{DS}$, the peak intensity of $\mathrm{O}-\mathrm{H}$ stretch for carboxylic acids at $3400-3450 \mathrm{~cm}^{-1}$ is weakened, which indicates that the hydroxyl group was participated in the reaction. In Fig. 1,

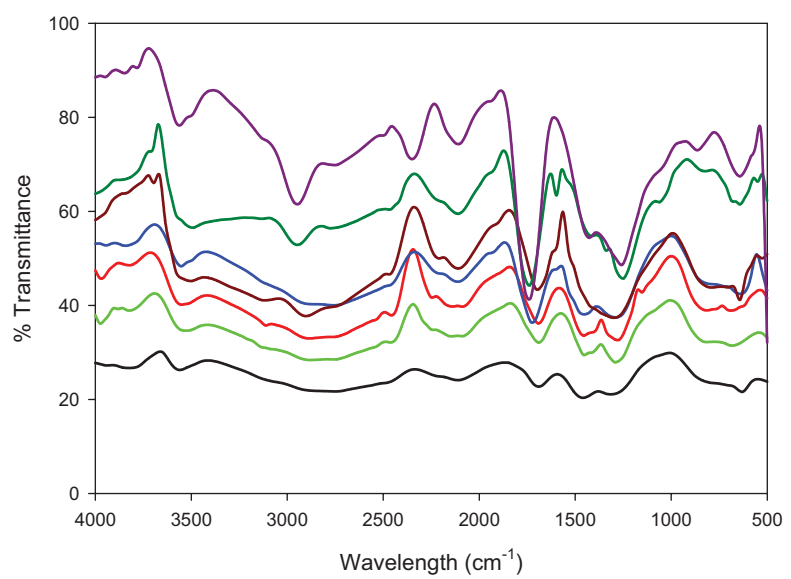

Figure 1. FTIR spectra of native sago starch and starch acetate. Spectra from top to bottom corresponding to (1) Native starch, (2) DS $=0.1$, (3) DS $=0.2$, (4) DS $=0.3$, (5) $\mathrm{DS}=0.6$, (6) DS $=0.8$, and (7) DS $=1.2$. the peak in the region $1850-1760 \mathrm{~cm}^{-1}$ is not available, which indicates the product is free of unreacted acetic anhydride. The absence of spectra at $1700 \mathrm{~cm}^{-1}$ for the carboxylic group implies that the starch acetate obtained in this work is also free of acetic acid [23].

\subsection{XRD analysis}

Figure 2 shows the results of XRD analysis for native and acetylated sago starch. The spectrum of native sago starch shows an A-type crystal pattern typically for cereal starches [24-26], that are characterized by strong reflection at around $2 \theta$ of 17.2 and $18 .^{\circ}$ and a single peak at $23.1^{\circ}$. For acetylated starch, there is a doublet at around 17 and $18.1^{\circ}$ for A-type and a doublet at 21.2 and $26.6^{\circ}$ for B-type. This combination indicates that acetylated starch is typically a C-type starch. As discussed by Tester et al. [25], the A-type crystalline structure is relatively compact with a low water content, whereas the B-type crystal has a more open structure containing a hydrated helical core. Therefore, acetylation causes the transition from A- to B-type polymorphic forms, which shows that the ability of water absorption of acetylated sago starch is higher than that of native starch.

\subsubsection{Water absorption index (WAl) and water solubility index (WSI)}

Acetyl content shows a significant correlation with absorption and solubility of starch acetate (Fig. 2). Starch 
Table 4. The characteristic infrared frequencies for sago starch

\begin{tabular}{|c|c|c|c|c|c|c|}
\hline \multirow[b]{2}{*}{ Sago Starch } & \multicolumn{4}{|c|}{ Experiment Condition } & \multirow{2}{*}{$\begin{array}{l}\text { Frequency with } \\
\text { relative intensity for } \\
\text { C-C stretch aromatics } \\
\left(1500-1400 \mathrm{~cm}^{-1}\right)\end{array}$} & \multirow{2}{*}{$\begin{array}{l}\text { Frequency with relative intensity } \\
\text { for } C=O \text { stretching vibrations } \\
\text { of saturated aliphatic esters } \\
\left(1750-1735 \mathrm{~cm}^{-1}\right)\end{array}$} \\
\hline & A & $\mathrm{B}$ & $\mathrm{C}$ & $\mathrm{D}$ & & \\
\hline Native starch & & & & & $\begin{array}{l}1428 m \\
1454 m\end{array}$ & - \\
\hline $\mathrm{DS}=0.1$ & -1 & +1 & +1 & +1 & $1427 \mathrm{~s}$ & 1735 vw \\
\hline $\mathrm{DS}=0.2$ & +1 & -1 & -1 & +1 & 1423 w & $1736 \mathrm{~m}$ \\
\hline $\mathrm{DS}=0.3$ & +1 & -1 & -1 & -1 & $1429 \mathrm{~m}$ & $1747 \mathrm{~s}$ \\
\hline $\mathrm{DS}=0.6$ & +1 & +1 & +1 & +1 & 1422 w & $1735 \mathrm{~s}$ \\
\hline $\mathrm{DS}=0.8$ & -1 & -1 & +1 & -1 & $1429 \mathrm{~m}$ & $1749 \mathrm{~s}$ \\
\hline $\mathrm{DS}=1.2$ & +1 & -1 & +1 & -1 & $1433 w$ & 1750 vs \\
\hline
\end{tabular}

vw, very weak; w, weak; m, medium; s, strong; vs, very strong.

acetates with different DS showed higher WAI and WSI at room temperature in comparison to the native sago starch. WAI of starch acetate increases with increasing DS. However, this behavior is slightly different for WSI, which reaches maximum at a DS of 0.8 and subsequently diminishes with increasing DS. Similar observation was reported for corn and potato starches $[4,5,16]$. However, the value of DS maximum is lower than that of cornstarch and potato starch. This might be due to larger granule size of sago starch than that of corn and potato starches. The introduction of

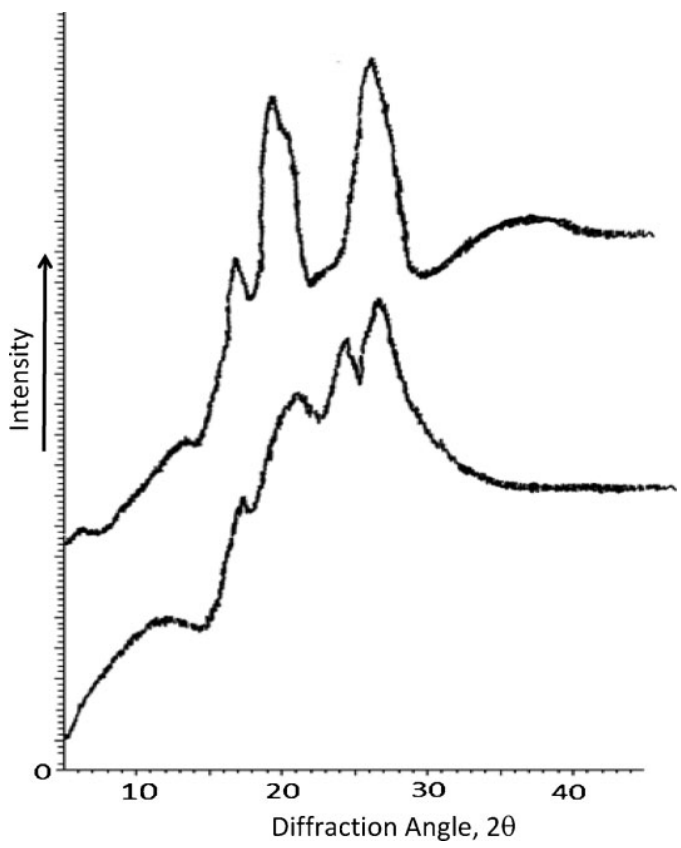

Figure 2. XRD diagram for native (top) and acetylated starch (DS = 1.2) (bottom). bulky acetyl into starch molecule by acetylation prevents the inter-chain association in the starch acetate, and enhances the access of water to the amorphous area. This could increase the hydration and swelling behavior of starch granule [27]. However, as DS increases, the amount of hydrophilic hydroxyl groups and the movement of water molecules within the starch molecules are reduced and as a result starch acetate becomes more hydrophobic [4].

In the acetylation, AM is the preferential site compared to AP, hence the swelling in water is mainly due to AP [14]. Therefore, for low DS, the AP is still substantial and is able to raise the water uptake in the granule. Surface erosion (Fig. 3) due to acetylation reaction indirectly affects the absorption and the solubility of starch acetate since this may promote the penetration of the water molecules, but this faculty could be reduced by the aggregation observed in high DS starch acetate.

\subsection{Morphological properties}

The granular structure of sago starches shows significant variations in size and shape with changing DS (Fig. 4). Native sago starch granules are smooth and irregularly oval. After acetylation, the structure of granule surface was changed. Aggregations and porosity on the surface of the acetylated starch granules increase with increasing DS. The acetylation treatment brought granule fusion that could be attributed to the introduction of hydrophilic group to the starch molecules and resulted in increasing hydrogen bonding. At the highest DS tried in this study (1.2), the structure of granules was significantly changed compared to that of native sago starch. The amount of acylation reagent used in acetylation affected granule fusion, especially when acetic anhydride was used $[5,16]$. 

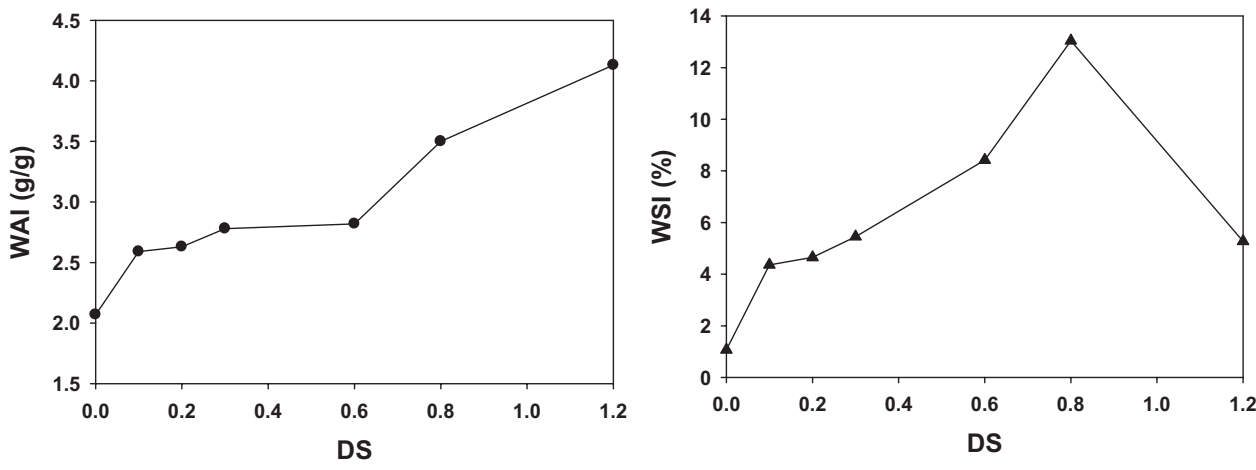

Figure 3. Relationship of DS and WAI (left) and WSI (right).
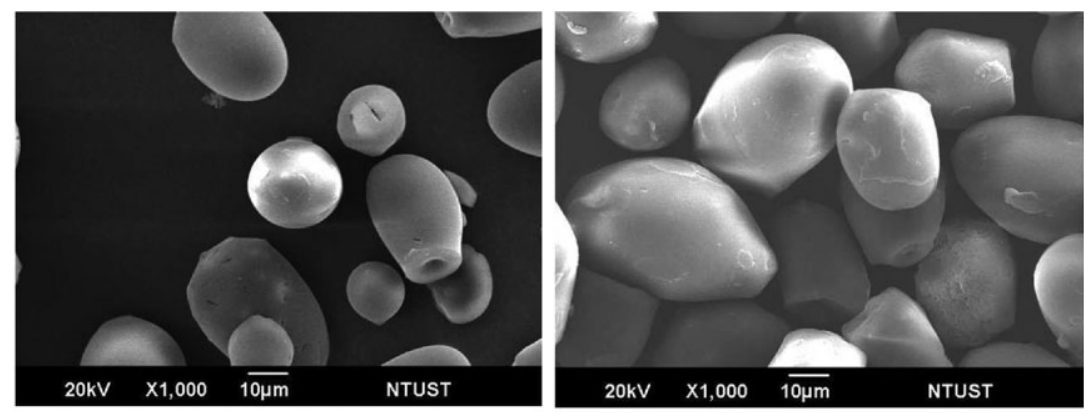

DS $=0.1$

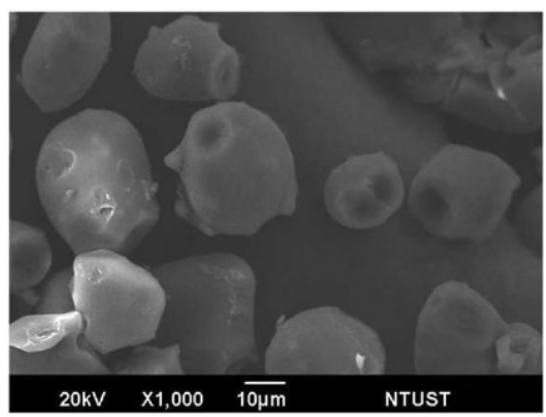

DS $=0.3$

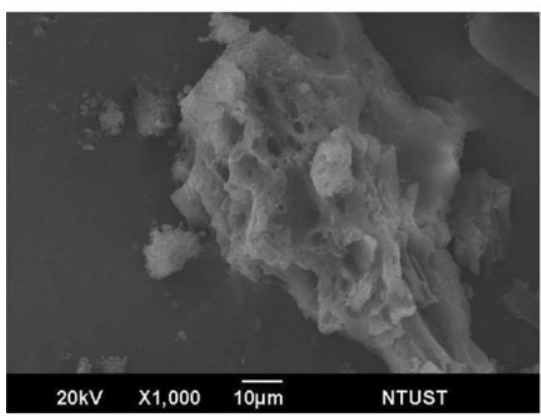

$\mathrm{DS}=\mathbf{0 . 8}$

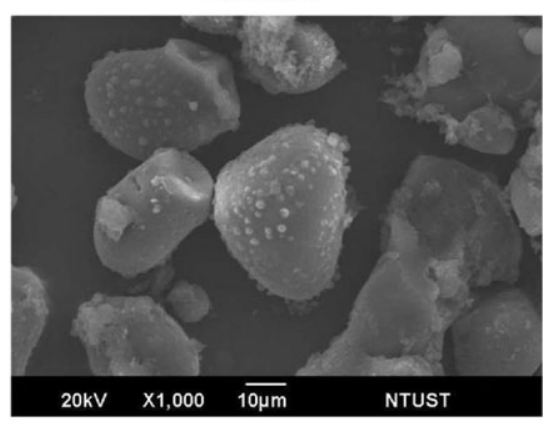

$\mathrm{DS}=\mathbf{0 . 6}$

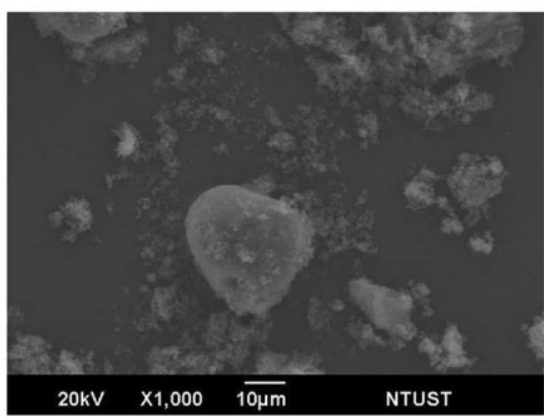

DS $=1.2$
Figure 4. Surface morphology of native sago starch and starch acetate using SEM $(1000 \times)$.

\section{Conclusions}

Sago starch acetate was synthesized under microwave radiation using iodine as the catalyst. Full factorial DOE was applied and it was shown that four variables measured in this experiment were significant in determining the
DS. The physicochemical characteristics of sago starch were observed using FTIR, WAI, and WSI. The starch acetate morphology was examined using SEM. The product obtained from this reaction is free of the acylation reagents, which is ready to be used for further applications. 
We thank to Prof Hwang Bing Joe from National Taiwan University of Science and Technology for the access of Microwave CEM Atmospheric Pressure. We also thank to Dr. David S. Barkley (Managing Editor, Virtlab) for the proof-reading.

The authors have declared no conflict of interest.

\section{References}

[1] Ellen, R., Processing Metroxylon sagu Rottbell (Arecaceae) as a technological complex: A case study from South Central Seram, Indonesia. Econ. Bot. 2004, 58, 601-625.

[2] Abd-Aziz, S., Review - Sago starch and its utilisation. J. Biosci. Bioeng. 2002, 94, 526-529.

[3] Elomaa, M., Asplund, T., Soininen, P., Laatikainen, R. et al., Determination of the degree of substitution of acetylated starch by hydrolysis, ${ }^{1} \mathrm{H}$ NMR and TGA/IR. Carbohydr. Polym. 2004, 57, 261-267.

[4] Shogren, R. L., Biswas, A., Preparation of water-soluble and water-swellable starch acetates using microwave heating. Carbohydr. Polym. 2006, 64, 16-21.

[5] Singh, N., Chawla, D., Singh, J., Influence of acetic anhydride on physicochemical, morphological and thermal properties of corn and potato starch. Food Chem. 2004, 86, 601-608.

[6] Billmers, R. L., Tessler, M. M., National Starch and Chemical Investment Holding Corporation, Wilmington, Del., US 1994.

[7] Biswas, A., Shogren, R. L., Selling, G., Salch, J. et al., Rapid and enviromentally friendly preparation of starch esters. Carbohydr. Polym. 2008, 74, 137-141.

[8] Tessler, M. M., Billmers, R. L., Preparation of starch esters. J. Polym. Environ. 1996, 4, 85-89.

[9] Chen, L., Li, X., Guo, S., Acetylated starch-based biodegradable materials with potential biomedical applications as drug delivery systems. Curr. Appl. Phys. 2007, 7S1, e90-e93.

[10] Zeng, S., Wang, S. J., Xiao, M., Hans, D. M., Meng, Y., Preparation and properties of biodegradable blend containing poly (propylene carbonate) and starch acetate with different degree of substitution. Carbohydr. Polym. 2011.

[11] Liebert, T., Kulicke, W.-M., Heinze, T., Novel approach towards hydrolytically stable starch acetates for pysiological applications. React. Funct. Polym. 2008, 68, 1-11.
[12] Koroskenyi, B., McCarty, S. P., Microwave-assisted solventfree or aqueous-based synthesis of biodegradable polymers. J. Polym. Environ. 2002, 10, 93-104.

[13] Singh, A. V., Nath, L. K., Manisha, G., Synthesis and characterization of highly acetylated sago starch. Starch/Stärke 2011, 63, 523-527.

[14] Huang, J., Schols, H. A., Klaver, R., Jin, Z., Voragen, A. G. J., Acetyl substitution pattern of amylose and amylopectin populations in cowpea starch modified with acetic anhydride and vinyl acetate. Carbohydr. Polym. 2007, 67, 542-550.

[15] Biswas, A., Shogren, R. L., Willett, J. L., Solvent-free process to esterify polysaccharides. Biomacromolecules 2005, 6, 1843-1845.

[16] Diop, C. I. K., Li, H. L., Xie, B. J., Shi, J., Effect of acetic acid/ acetic anhydride ratios on the properties of corn starch acetates. Food Chem. 2011, 126, 1662-1669.

[17] Biswas, A., Selling, G., Appell, M., Woods, K. K. et al., lodine catalyzed esterification of cellulose using reduced levels of solvent. Carbohydr. Polym. 2007, 68, 555-560.

[18] Kruger, L. H., Rutenberg, M. W., Production and Uses of Starch Acetates, New York Academic Press, New York 1967.

[19] Bass, I., Six Sigma Statistics with Excel and Minitab, McGraw-Hill, New York 2007.

[20] Brelid, P. L., Simonson, R., Acetylation of solid wood using microwave heating. Eur. J. Wood Wood Prod. 1999, 57, 383-389.

[21] Feuer, B. I., Heights, B., in: office, U.P. (Ed.), US 1998.

[22] Chi, H., Xu, K., Wu, X., Chen, Q. et al., Effect of acetylation on the properties of corn starch. Food Chem. 2008, 106, 923928.

[23] Li, J., Zhang, L. P., Peng, F., Bian, J. et al., Microwaveassisted solvent-free acetylation of cellulose with acetic anhydride in the presence of iodine as a catalyst. Molecules 2009, 14, 3551-3566.

[24] Colonna, P., Buleon, A., Mercier, C., Pisum sativum and Vicia faba carbohydrates: Structural studies of starches. J. Food Sci. 1981, 46, 88-93.

[25] Tester, R. F., Karkalas, J., Qi, X., Starch-composition, fine structure and architecture. J. Cereal Sci. 2004, 39, 151-165.

[26] Ahmad, F. B., Williams, P. A., Doublier, J.-L., Durand, S., Buleon, A., Physico-chemical characterisation of sago starch. Carbohydr. Polym. 1999, 38, 361-370.

[27] Xu, Y. X., Dzenis, Y., Hanna, M. A., Water solubility, thermal characteristics and biodegradability of extruded starch acetate foams. Ind. Crops. Int. J. 2005, 21, 361-368. 